УДК 339.3

DOI 10.31882/2311-4711.2019.25.7

\author{
Зверева Анна Олеговна \\ к.э.н., дочент, кафедра торговой политики \\ Российский экономический университет имени Г.В.Плеханова, \\ Российская Федераџия, г. Москва, 117997, Стремянный пер., 36 \\ E-mail:sw_an@mail.ru
}

\title{
КАЧЕСТВО ОБСЛУЖИВАНИЯ КАК ФАКТОР ЭФФЕКТИВНОСТИ ВНЕМАГАЗИННОЙ ТОРГОВЛИ В УСЛОВИЯХ ЦИФРОВИЗАЦИИ
}

Аннотация. В статье исследованы проблемы трактовки понятия качества торгового обслуживания в контексте трансформации торговых услуг в условиях цифровизации экономики. Внемагазинные формы торговых услуг, особенно интернет-торговля, приобретают сегодня возрастающее значение. В свете этого набор традиционных параметров, определяющих качество обслуживания необходимо расширять. Их перечень в условиях глобального влияния интернет-компаний должен учитывать специфику оказания торговых услуг в цифровой среде.

Ключевые слова: качество торгового обслуживания, торговые услуги, внемагазинные формы продаж, интернет-торговля.

Введение. Качество торгового обслуживания - один из ключевых аспектов формирования социально-экономической эффективности деятельности как отдельных торговых структур, так и торговли в целом. Анализу качества торгового обслуживания в розничной торговле посвящено достаточное количество теоретических источников $[1,2]$.

Однако, учитывая определенную специфику внемагазинной торговли, особенно в интернет-среде, необходимо отметить, что полное отождествление характеристик, присущих качеству обслуживания в традиционной розничной и внемагазинной торговле, представляется ошибочным. В этой связи актуально сопоставление трактовок понятия качества торгового обслуживания в традиционной и внемагазинной розничной торговле $[3,4]$.

Основная часть. Наиболее широко представлены теоретические толкования понятия качества торгового обслуживания в традиционной розничной торговле. Так, Леви М., Вейтц Б.А. под качеством торгового обслуживания понимают «набор действий и программ, направленных на улучшение процесса совершения покупки» [6, с. 357]. Ферни Дж. рассматривает категорию качество торгового обслуживания как «...предоставление розничной компанией оборудования, деятельности, преимуществ, создание атмосферы в дополнение к основной сделке - обмену товара на деньги» [8, с. 360]. Н.Н. Терещенко и С.В. Трусова под качеством торговых услуг, как составной компоненты понятия «обслуживание» понимают степень соответствия детерминант предоставляемых услуг совокупности конкретных потребностей и ожиданий рыночных субъектов с учетом цены, которую они готовы заплатить за данный вид услуги, и полезности услуг с точки зрения эффективности процессов обмена [5]. При этом качество торгового обслуживания представляет собой набор характеристик, отражающих свойства товаров с точки зрения их потребительной стоимости и условий процесса торгового обслуживания. При этом важно иметь ввиду максимальное соответствие ожиданиям потребителя относительно качества торгового обслуживания в предприятиях розничной торговли $[6,7]$.

При наличии большого количества трактовок, мы, однако, придерживаемся мнения, при оценке качества торгового обслуживания вообще, необходимо анализировать набор характеристик, таких как представленный ассортимент и качество товара, и применяемые методы обслуживания, и мерчандайзинг, и дополнительные услуги и т.п.

Обобщив мнение большинства исследователей, можно сделать вывод о том, что качество торгового обслуживания является одним из элементов необходимых для формирования и повышения уровня социально-экономической эффективности торговых организаций, оценить которое возможно посредством установления соответствия ожиданий потребителей их восприятию.

Естественно качество торгового обслуживания не возникает само по себе, а формируется под воз- 
действием определённых факторов, и, в свою очередь, является важнейшим фактором, обуславливающим успех работы конкретного предприятия [8, 9]. Если уровень качества торгового обслуживания невысок, то добиться экономической эффективности (прибыльной, рентабельной работы) в розничной торговле в принципе возможно, но достичь социально-экономической эффективности представляется проблематичным. Заметим, что достижение и поддержание качества торгового обслуживания представляет собой комплексный процесс, включающий и постоянное совершенствование квалификации персонала, и своевременную модернизацию материально-технической базы, и неизменную корректировку ассортиментного портфеля.

Поскольку в составе услуг розничной торговли выделят несколько составных элементов: реализацию товаров, оказание помощи покупателям в приобретении товаров, информационно-консультационные услуги и дополнительные (прочие) услуги, в современной среде услуги в значительной степени трансформируются под влиянием внешних тенденций.

Услуги розничной торговли являются важным (а иногда и определяющим) фактором, оказывающим существенное влияние на формирование качества торгового обслуживания. Но вместе с тем необходимо отметить и обратную зависимость - высокое качество обслуживания должно в значительной степени определять высокий уровень оказываемых розничной торговой организацией услуг. Инструменты цифровой экономики, омниканальный подход предоставляет новые возможности к повышению качества торгового обслуживания [10].

Если анализу качества обслуживания в традиционной розничной торговле уделено значительное внимание и посвящено достаточное количество теоретических работ, то проблемам качества торгового обслуживания при использовании внемагазинных форм торговли уделено явно недостаточно внимания. Особенности внемагазинной торговли, характеристики, позволяющие рассматривать внемагазинные формы торговли и как своеобразное дополнение внутренней розничной торговли, и как относительно самостоятельный вид деятельности, обуславливают иной (отличный от традиционной розничной торговли) состав показателей качества торгового обслуживания $[11,12]$.

Вместе с тем, состав показателей качества торгового обслуживания должен отвечать требованиям, предъявляемым нормативными документами и к услугам традиционной розничной торговли. Специфику качества обслуживания при применении внемагазинных форм продаж, в значительной степени, на наш взгляд, определяют технические и технологические особенности, присущие разновидностям внемагазинной торговли $[13,14]$. Соответственно, и показатели качества обслуживания при использовании любых разновидностей внемагазинной торговли должны учитывать эти особенности. Показатели качества обслуживания во внемагазинной торговле должны существенно отличаться от показателей качества обслуживания в традиционной розничной торговле из-за наличия большого числа технологически различающихся разновидностей (сюда можно добавить доступность торговых онлайн услуг, включая вариативность способов доставки товаров). Поэтому они в значительной степени, должны проецировать факторы внешней среды, которые определяют развитие внемагазинной торговли в целом (например, развитие интернет-торговли, увеличение доли заказов с использование онлайн технологий). Следовательно, качество торгового обслуживания является, с одной стороны, фактором, определяющим социально-экономическую эффективность функционирования, с другой - влияет на определение вектора развития внемагазинных форм торговли.

Заключение. В условиях цифровизации внешней среды понятие качества торгового обслуживания дополняется рядом характеристик. Сюда можно отнести доступность услуг с использованием различных технических устройств, скорость и удобство обработки заказа потребителя, вариативность способов расчетов и доставки. Расширяя перечень традиционных параметров и учитывая их в практической работе организации торговли способны достичь планируемые показатели эффективности хозяйственной деятельности включая экономическую и социальную компоненты.

\section{Список использованных источников}

1. Алексина С.Б., Иванов Г.Г., Крышталев В.К., Панкина Т.В. Методы стимулирования продаж в торговле. Москва, 2013.

2. Депутатова Е.Ю., Зверева А.О. Качество торгового обслуживания как фактор конкурентоспособности в эпоху глобализации//Российское предпринимательство. 2018. Т. 19. № 11. С. 3403-3412.

3. Иванов Г.Г. Методология трансформации потенциала развития торговых организаций. - диссертация на соискание ученой степени доктора экономических наук / Российский экономический университет им. Г.В. Плеханова. Москва, 2006 
4. Vashchekina I. V., Vashchekin A. N. Social responsibility policy of Russian credit organizations in a recession // European Journal of Natural History. 2016. № 3. C. 106-110.

5. Косов М.Е. Равновесие экономической системы/Монография Российский государственный торгово-экономический университет. РГТЭУ Москва 2012 год. С. 295.

6. Кадацкая Д.В. Оценка качества торгового обслуживания потребителей//Вестник Белгородского университета кооперации, экономики и права. 2012. № 1 (41). С. 410-416.

7. Быканова О.А., Ахмадеев Р.Г. Диверсификация портфельных инвестицй суверенных фондов // Азимут научных исследований: экономика и управление. 2016. Т. 5. № 4 (17). С. 59-63.

8. Леонова Ю.Г. Методические аспекты оценки эффективности функционирования торговой организации на основе клиентоориентированного подхода - Сборник материалов конференции: Современные тенденции и перспективы развития торговой отрасли Российской Федерации - Уфа, 2016.- С. 106-126.

9. Леви М., Вейтц Б.А. Основы розничной торговли [Текст]. - Спб.: Питер, 2001.- 448 с.

10. Бухгалтерский финансовый учет: учебник /Бухарева Л.В., Малицкая В.Б., Чиркова М.Б. и.др..-М.: Издательство Юрайт, 2016.-539c.

11. Голубцова Е.В. Налоговое регулирование внешнеторговой деятельности в Российской Федерации: учебное пособие. -М.: ГОУ ВПО «РЭУ им. Г.В. Плеханова», 2011. -80 с.

12. Чайковская Л.А., Галайда А.М. Проблемы гармонизации бухгалтерского и налогового учета основных средств // Экономика и управление: проблемы, решения. 2017. Т. 2. № 8. С. 36-44.

13. Терещенко Н.Н., Трусова С.В. Методологические подходы к оценке качества услуг предприятий розничной торговли. Монография/Н.Н. Терещенко, С.В. Трусова; М-во образования и науки Российской Федерации, Федеральное гос. бюджетное образовательное учреждение высш. проф. образования „Красноярский гос. торгово-экономический ин-т“. Красноярск, 2011.

14. Ферни Дж. Принципы розничной торговли [Текст]. - М.:ЗАО «Олимп-Бизнес», 2008. - 416 с.

\author{
Zvereva Anna Olegovna \\ Ph.D., Associate professor, Department of Accounting and Taxation \\ Plekhanov Russian University of Economics, \\ Russian Federation, 117997, Moscow, Stremyanny lane, 36 \\ E-mail:sw_an@mail.ru
}

\title{
QUALITY OF SERVICE AS A FACTOR OF THE EFFICIENCY OF OUT-GAS TRADE UNDER CONDITIONS OF DIGITAL TRENDS
}

Summary. This article examines the problems of interpreting the concept of quality of trade services in the context of the transformation of trade services in a digitalizing economy. Out-of-store forms of trading services, especially e-commerce, are becoming increasingly important today. In light of this, the set of traditional parameters that determine the quality of service should be expanded. Their list in the context of the global influence of Internet companies should take into account the specifics of the provision of trading services in the digital environment.

Keywords: quality of trade services, trade services, non-store forms of sales, online trading. 